Research Article

\title{
A Performance Study of Home-Made Co-Immobilized Lipase from Mucor miehei in Polyurethane Foam on The Hydrolysis of Coconut Oil to Fatty Acid
}

\author{
Dwina Moentamaria, Maktum Muharja, Tri Widjaja, Arief Widjaja*
}

Department of Chemical Engineering, Institut Teknologi Sepuluh Nopember, Jl. Arief Rahman Hakim, Kampus ITS Sukolilo, Surabaya 60111, Indonesia

Received: $7^{\text {th }}$ December 2018; Revised: $11^{\text {st }}$ February 2019; Accepted: $15^{\text {th }}$ February 2019; Available online: 30th April 2019; Published regularly: 1st August 2019

\begin{abstract}
Bio-based fatty acids (FAs) produced through hydrolysis of natural oils and fats are promising chemical feedstocks for increasing the economic value of renewable raw materials. In this work, lecithin, gelatin, PEG, and $\mathrm{MgCl}_{2}$ were employed as the co-immobilized material of crude lipase Mucor miehei immobilization on the polyurethane foam (PUF) matrix for hydrolysis of coconut oil to Free Fatty Acid (FFA). The unconventional immobilized technique was used through cross-linking and covalent bond. Single factor analysis and response surface method were utilized to determine the optimum conditions of the hydrolysis reaction. After optimization, co-immobilized lipase was examined for storage stability at a temperature of $4^{\circ} \mathrm{C}$ and reusability performance. The optimum conditions for coconut oil hydrolysis were obtained on the co-immobilized-PUF ratio, water-oil ratio, and reaction time of $20.17 \mathrm{w} / \mathrm{w}, 4.45$ $\mathrm{w} / \mathrm{w}$, and $20 \mathrm{~h}$, respectively. Under these conditions, the acid value as lauric acid enhanced $573 \%$ to $3.21 \mathrm{mg} \mathrm{KOH} / \mathrm{g}$ oil. Storage stability attained through remaining activity on free lipase, PUF-lipase, PUF-co-immobilized-lipase were $9.89 \%, 42.3 \%$, and $91.88 \%$, respectively. In this study, the application of PUF-co-immobilized lipase in hydrolysis reactions can be reused up to 5 times. Characteristics of the addition of co-immobilized lipase have been analyzed using Fourier Transform Infra Red (FTIR) and Scanning Electron Microscope (SEM), showing the presence of functional groups binding and the changes in the surface matrix structure. Copyright ( 2019 BCREC Group. All rights reserved
\end{abstract}

Keywords: co-immobilized lipase; coconut oil; free fatty acid; polyurethane foam; response surface methodology

How to Cite: Moentamaria, D., Muharja, M., Widjaja, T., Widjaja, A. (2019). A Performance Study of Home-Made Co-Immobilized Lipase from Mucor miehei in Polyurethane Foam on The Hydrolysis of Coconut Oil to Fatty Acid. Bulletin of Chemical Reaction Engineering \& Catalysis, 14(2): 391-403 (doi:10.9767/bcrec.14.2.3848.391-403)

Permalink/DOI: https://doi.org/10.9767/bcrec.14.2.3848.391-403

\section{Introduction}

The production of fatty acids through hydrolysis of natural oils and fats is important to increase the economic value of renewable raw materials. Fatty acids are widely used in the food,

* Corresponding Author.

Email: arief_w@chem-eng.its.ac.id (A. Widjaja);

Telp: +62-31-5946240, Fax: +62-31-5999282 cosmetic, pharmaceutical, and chemical industries such as flavor, omega three fatty acids, emulsifiers, coatings, adhesives, and fragrances. Oils and fats, which are composed of fatty ester or triglyceride components, can produce free fatty acids (FFA) and glycerol by using chemical or enzymatic hydrolysis reactions [1-3]. The enzymatic reaction using lipase as biocatalyst in mild condition is an attractive green process be- 
cause it is not only able to increase energy efficiency but also eliminate by-product reactions compared to steam splitting process [2,4-6].

The use of free enzymes on enzymatic methods is still limited due to the high cost of isolation and purification and has a labile nature leading to denaturation and reduction of enzyme activity. Moreover, it is necessary to separate dissolved products from the free enzymes. Therefore, immobilization techniques by which the enzyme is not free to move are required. Although immobilized enzyme have limited space for their catalytic activities, they can be reused repeatedly, and the stability of the enzyme can be increased against temperature and organic solvent as well as an increase conversion yields $[2,7,8]$.

The development of immobilization lipase technology has been broadly applied to hydrolysis, esterification, transesterification, interesterification by using various matrix. The use of lipase immobilization has been shown to provide higher stability, reusability, practicability and activity response than lipase-free [3,9-11]. On the other studies, a combination of two immobilization techniques, namely crosslinkingcovalent, adsorption-crosslinking, and crossentrapment, showed higher stability compared to using only one immobilization technique $[9,12,13]$. Among all available immobilization matrix, polyurethane foam (PUF) has higher commercial prospects since it is inert, rigid, porous, and inexpensive. PUF has been widely used as a matrix to covalently immobilize lipase [14-16].

In some processes, co-immobilization agents have positive functions and clear synergies in enzymatic hydrolysis where the enzyme binds to the matrix functional group to be more stable $[13,17,18]$. In the previous study, mixtures of additives, surfactants, emulsifiers, and cofactors were used as co-immobilized lipases $[19,20]$. Some of these substances can be synergized together and serve as penetration of substrate entry because they are well dispersed, resulting in low turbidity and excellent stability. Also, the co-immobilization agent can protect from inactivation, increasing the enzyme activity several times after the initial activity of the enzyme [4,21].

Generally, hydrolysis is carried out using chemical substrates and commercial lipases. The phenomenon occurred in the reaction process conditions using a co-immobilized lipase mixture on the PUF matrix using natural substrates, non-commercial as home-made lipases, free solvents that have an impact on yield (as acid value) has never been discussed and reported before.

From aforementioned problem above, the home-made co-immobilized lipase of $M$. miehei was utilized to catalyze the hydrolysis process of coconut oil into FFA through an unconventional crosslinking and covalent bonding. Response surface methodology (RSM) was used as a tool to optimize the hydrolysis process. The effect of some important parameters such as co-immobilized lipase-PUF ratio, water-oil ratio and incubation time of hydrolysis was investigated and discussed comprehensively.

\section{Materials and Methods}

\subsection{Materials}

Coconut oil (purity of 100\%) was obtained from local Permata Agrindo Pendowoharjo (Sewon, Bantul, Indonesia) with the commercial name Laitco. The stock culture of M. miehei is obtained from Biochemical Technology Laboratory, Department of Chemical Engineering, Sepuluh Nopember Institute of Technology Surabaya. Co-immobilized consisting of gelatin, lecithin, polyethylene glycol (PEG), $\mathrm{MgCl}_{2}$ was purchased from Merck (Darmstadt, Germany). PUF was made by reacting isocyanate and polyol with the same volume ratio [22,23].

\subsection{Methods and Techniques}

\subsubsection{Production of crude lipase from M. miehei}

M. miehei culture stock in Potato Dextrose Agar (PDA) was mixed with $10 \mathrm{~mL}$ of sterile water. The $10^{7}$ spores $/ \mathrm{mL}$ was inoculated on sterile media containing $\mathrm{KH}_{2} \mathrm{PO}_{4}, \mathrm{FeSO}_{4} .7 \mathrm{H}_{2} \mathrm{O}$, olive oil, palm oil, dried coconut grout (solid), and water at $\mathrm{pH}$ of 7 . Cells were incubated at solid state fermentation at $37^{\circ} \mathrm{C}$ for 5 days.

Crude lipase was obtained by extracting with phosphate buffer with a buffer to media ratio of 4: $1(\mathrm{w} / \mathrm{w})$ in incubator shaker at 150 $\mathrm{rpm}, 37^{\circ} \mathrm{C}$, for $135 \mathrm{~min}$. The filtration was carried out to separate solid to crude lipase liquid. The supernatant was then analyzed for its lipase activities using olive oil as substrate [24,25].

2.2.2 Preparation of unconventional immobilization lipase through cross- linking and covalent methods.

Matrix PUF is a cuboid shaped porous matrix measuring $0.5 \mathrm{~cm} \times 0.5 \mathrm{~cm} \times 0.5 \mathrm{~cm}$. Previously prepared co-immobilized solution contained a) lechitin $(50 \mathrm{~g} / \mathrm{L})$, b) gelatin $(50$ $\mathrm{g} / \mathrm{L})$, c) $\mathrm{MgCl}_{2}(10 \mathrm{~g} / \mathrm{L})$, d) PEG $6000(20 \mathrm{~g} / \mathrm{L})$ 
[22,23]. PUF and co-immobilized were prepared with a ratio of $1: 15,1: 20,1: 25(\mathrm{w} / \mathrm{w})$. Then the PUF and co-immobilized were immersed for 30 min and incubated at $30^{\circ} \mathrm{C}$. Immobilized PUF was filtered, dried in a $30^{\circ} \mathrm{C}$ oven for $1 \mathrm{~h}$. Then it was soaked in crude lipase for $24 \mathrm{~h}$ and then dried at room temperature.

\subsubsection{Hydrolysis of coconut oil}

The hydrolysis of coconut oil to FFA was determined by its acid value. Coconut oil of $10 \mathrm{~g}$ was hydrolyzed with water under a certain ratio $(\mathrm{w} / \mathrm{w})$, incubated at $40{ }^{\circ} \mathrm{C}$ with a certain time. The hydrolysate was then separated and analyzed using the titrimetric acid value based on following Equation (1).

$$
\text { Acid value }=\frac{v \mathrm{KOH}(\mathrm{ml}) \times \mathrm{C} \mathrm{KOH}(\mathrm{N}) \times 56.1}{\text { Oil sample }(\mathrm{gr})}
$$

\subsubsection{Single factor experiment}

The effect of stirring was determined using orbital shaker velocity of $0,60,90,120,150$, and $180 \mathrm{rpm}$ in coconut oil hydrolysis process on water oil ratio $5: 1$, hydrolysis incubation time $15 \mathrm{~h}$, co-immobilized lipase to PUF 20:1 . The influence of water to oil has been determined by different ratio of water: oil of $0.6: 1$, $1: 1,3: 1,5: 1$, and $7: 1$ at $10 \mathrm{~h}$ incubation time hydrolysis, co-immobilized lipase to PUF = 20:1, $120 \mathrm{rpm}$. Effect of hydrolysis incubation time of $2,5,10,15,20$, and $25 \mathrm{~h}$ in coimmobilized ratio against PUF of 15:1 (w/w), water oil ratio of $5: 1(\mathrm{w} / \mathrm{w})$ was studied. The effect of co-immobilized lipase on PUF has been determined by varying ratio of co-immobilized: PUF of 10:1, 15:1, 20:1, 25:1, and 30:1.

\subsubsection{RSM design and statistical analysis}

Based on the initial experimental data generated on the single factor experiment, a Box-Behnken design was utilized to determine the effect of the three independent variables of co-immobilized lipase:PUF ratio, water-oil ratio, and hydrolysis incubation time as shown in Table 1.

Table 1. Independent variables and their levels use in the response using Box-Behnken design

\begin{tabular}{lcccc}
\hline \multicolumn{1}{c}{ Independent variables } & Code & \multicolumn{3}{c}{ Factor levels } \\
\cline { 3 - 5 } & & $-1(-\alpha)$ & 0 & $+1(+\alpha)$ \\
\hline Co-immobilized lipase : PUF ratio (w/w) & $\mathrm{A}$ & 15 & 20 & 25 \\
Water : oil ratio (w/w) & $\mathrm{B}$ & 1 & 3 & 5 \\
Hydrolysis incubation time $(\mathrm{h})$ & $\mathrm{C}$ & 10 & 15 & 20 \\
\hline
\end{tabular}

Table 2. Box-Behnken design and the acid value observed

\begin{tabular}{cccccccc}
\hline \multirow{2}{*}{ Run } & \multicolumn{3}{c}{ Actual variable } & & \multicolumn{3}{c}{ Acid value (mg KOH/g oil) } \\
\cline { 2 - 3 } \cline { 6 - 7 } \cline { 6 - 7 } & A (co/PUF) & $\mathrm{B}(\mathrm{W} / \mathrm{O})$ & $\mathrm{C}(\mathrm{h})$ & & Experimental & Predicted & Residue \\
\hline 1 & 20 & 3 & 15 & & 2.4678 & 2.7581 & -0.2903 \\
2 & 20 & 3 & 15 & & 2.4678 & 2.7581 & -0.2903 \\
3 & 15 & 3 & 10 & & 1.2266 & 1.2286 & -0.0020 \\
4 & 20 & 3 & 15 & & 2.4678 & 2.7581 & -0.2903 \\
5 & 25 & 5 & 15 & & 1.4618 & 2.2493 & -0.7875 \\
6 & 15 & 3 & 20 & & 1.4830 & 1.9645 & -0.4815 \\
7 & 15 & 1 & 15 & & 0.9652 & 1.0164 & -0.0512 \\
8 & 20 & 5 & 10 & & 1.9612 & 2.9780 & -1.0168 \\
9 & 25 & 1 & 15 & & 0.9935 & 0.9476 & 0.0459 \\
10 & 15 & 5 & 15 & & 1.2199 & 2.1045 & -0.8846 \\
11 & 20 & 3 & 15 & & 2.4678 & 2.7581 & -0.2903 \\
12 & 25 & 3 & 10 & & 1.1246 & 1.2236 & -0.0990 \\
13 & 20 & 1 & 20 & & 2.7401 & 2.5620 & 0.1781 \\
14 & 20 & 3 & 15 & & 2.4678 & 2.7581 & -0.2903 \\
15 & 20 & 1 & 10 & & 1.4728 & 1.7742 & -0.3014 \\
16 & 20 & 5 & 20 & & 3.2107 & 3.7480 & -0.5373 \\
17 & 25 & 3 & 20 & & 1.4670 & 2.0455 & -0.5785 \\
\hline
\end{tabular}


Complete design which consists of 17 experiments including 6 repetitions on the center point was run randomly. Table 2 shows the run order, variable conditions, and experimental and predictive values. After determining the preliminary range of hydrolysis through the single factor test, the relationships between the response and three selected variables were approximated by the following second order polynomial equation as shown in Equation (2).

Acid value $(\mathrm{mg} \mathrm{KOH} /$ gram oil $)=\beta_{0}$

$$
\begin{aligned}
& +\sum_{i=1}^{3} \beta_{i} X_{i}^{2}+\sum_{i=1}^{3} \beta_{i i} X_{i}^{2} \\
& +\sum_{i<j=2}^{3} \beta_{i j} X_{i} X_{j}
\end{aligned}
$$

Where $X_{i}$ is the corresponding actual value of variable, $\beta_{0}$ is the estimated regression coefficient of the fitted response at centre point of design, $\beta_{i}$ is regression coefficient for liner effect terms, $\beta_{i j}$ is interaction effects, and $\beta_{i i}$ is quadratic effects.

Data were analyzed by ANOVA to determine the effect of linear, quadratic, and interaction variables on the hydrolysis of coconut oil using co-immobilized lipase. Data analysis and RSM are carried out with a commercial statistical package, Design-Expert version 9.0.4.1 (Minneapolis, USA). The surface and contour plot revealed the effect of all factors at a central point in the design space.

\subsubsection{Characterization of substrate and product}

Acid value of coconut oil and fatty acid were analyzed by AOCS method [1]. Fatty acid composition was determined using GC-MS. To 4 drops of the sample in a test tube, $4 \mathrm{~mL}$ of hexane (p.a) was added, vortexed for $2 \mathrm{~min}$. The clear hexane extract was transferred to a derivatization tube and dried with nitrogen bursts. Then $2 \mathrm{~mL}$ of $2 \% \mathrm{NaOH}$ in methanol was heated at $90{ }^{\circ} \mathrm{C}$ for $5 \mathrm{~min}$. After cooling, addition of $2 \mathrm{~mL}$ of BF3 in methanol, and reheat for 30 min. After cooling the sample was extracted with $3 \mathrm{~mL}$-hexane (p.a). The upper phase (nHexane) was taken for analysis with GC-MS (Agilent 6980 N, Santa Clara United States). The detector was Inert MSD Agilent 5973 detector. The column J\&W Scientific HP-5\% phenylmethylsiloxane $30 \mathrm{~m}$ length, $0.32 \mathrm{~mm}$ i.d, $0.25 \mu \mathrm{m}$ film thickness. The detector temperature was $280{ }^{\circ} \mathrm{C}$; the column temperature was held at $170{ }^{\circ} \mathrm{C}$ for $1 \mathrm{~min}$ increased to $180{ }^{\circ} \mathrm{C}$ at $2{ }^{\circ} \mathrm{C} / \mathrm{min}$, increased 270 ${ }^{\circ} \mathrm{C}$ at $5{ }^{\circ} \mathrm{C} / \mathrm{min}$, and held at $270{ }^{\circ} \mathrm{C}$ for $3 \mathrm{~min}$. The carrier gas was helium at a flow rate of 1 $\mathrm{mL} / \mathrm{min}$.

\subsubsection{Analytical method}

The activity of crude lipase was determined using olive oil as a substrate. $25 \mathrm{~mL}$ of olive oil and $75 \mathrm{ml}$ of $7 \%$ solution of gum arabic were emulsified for $2 \mathrm{~min}$. Furthermore, $5 \mathrm{~mL}$ of the emulsified olive oil was mixed with $2 \mathrm{~mL}$ of 0.1 $\mathrm{M}$ phosphate buffer ( $\mathrm{pH} 7)$ and $1 \mathrm{~mL}$ of the enzyme suspension. The mixture was incubated at $37^{\circ} \mathrm{C}$ for $30 \mathrm{~min}$ with an orbital shaker. After incubation, the reaction was stopped by the addition of $15 \mathrm{~mL}$ of acetone-ethanol $(1: 1 \mathrm{v} / \mathrm{v})$ and the FFA was titrated with $0.05 \mathrm{M} \mathrm{NaOH}$. A unit of lipase activity is defined as a number of enzymes capable of liberating $1 \mu \mathrm{mol}$ of fatty acids per min $[25,26]$. Lipase activity can be calculated by the following Equation (3).

$$
\text { Lipase Activity }(U / m l)=\frac{(a-b) \times N ~ N a O H \times 1000}{t}
$$

Where, $a$ and $b$ is the amount of $\mathrm{NaOH}$ required for the sample titration using lipase and without lipase $(\mathrm{ml})$, respectively, and $t$ is the incubation time (30 $\mathrm{min})$. The matrix activity was determined in the same manner as above, but the $1 \mathrm{ml}$ crude sample was substituted by co-immobilized lipase-PUF $1 \mathrm{~g}$.

Residual TAGs were analyzed using LC MS/MS. Accella 1250 LC-MS/MS (Thermo Scientific-Waltham, MA USA) was equipped by Hypersil Gold column $(50 \mathrm{~mm} \times 2.1 \mathrm{~mm} \times 1.9$ $\mu \mathrm{m})$. The mobile phase of $2 \mu \mathrm{L}$ was employed at a flow rate of $300 \mu \mathrm{L} / \mathrm{min}$. The column and autosampler was controlled at $30^{\circ} \mathrm{C}$ and $16^{\circ} \mathrm{C}$, respectively. The MS/MS Triple Q TSO Quantum Access Max mass spectrometer was operated in positive mode.

2.2.8 Characterization of co-immobilized lipasePUF

Morphology of PUF matrix with coimmobilized lipase were evaluated by SEM JEOL JSM-7800F (Pleasanton, California, United States). FTIR is a technique used to obtain an infrared spectrum of absorpsion of solid, liquid or gas. An FTIR spectrometer simultaneously collects high-spectral-resolution data over a wide spectral range FTIR spectra was analyzed using a Shimadzu IR Prestige 21 (Tokyo, Japan). The IR Prestige-21 uses a bright ceramic light source, high-sensitivity DLATGS detector, and high-throughput optical elements.

2.2.9 Storage stability and reusability calculation

The storage stability of the PUF-co- 
immobilized lipase was determined by measuring the activity at the time of week storage of 4 ${ }^{\circ} \mathrm{C}$, using Equation (4).

Activity analysis was carried out on free lipase, PUF-lipase and PUF-co immobilized lipase every week to analyze its degradation. Afacid was determined, and PUF-co-immobilized lipase was subjected to enzyme assay. The immobilized enzyme was then can be reused for subsequent reactions. The reusability of co immobilized lipase on PUF was determined by following Equation (4).

Remaining activity $(\%)=\left[\frac{\left(\text { activity at } t_{0}\right)-\left(\text { activity at } t_{r}\right)}{\left(\text { activity at } t_{r}\right)}\right]$

Where, activity at $t_{0}$ was defined as initial activity and activity at $t_{r}$ is activity after storage/ hydrolysis.
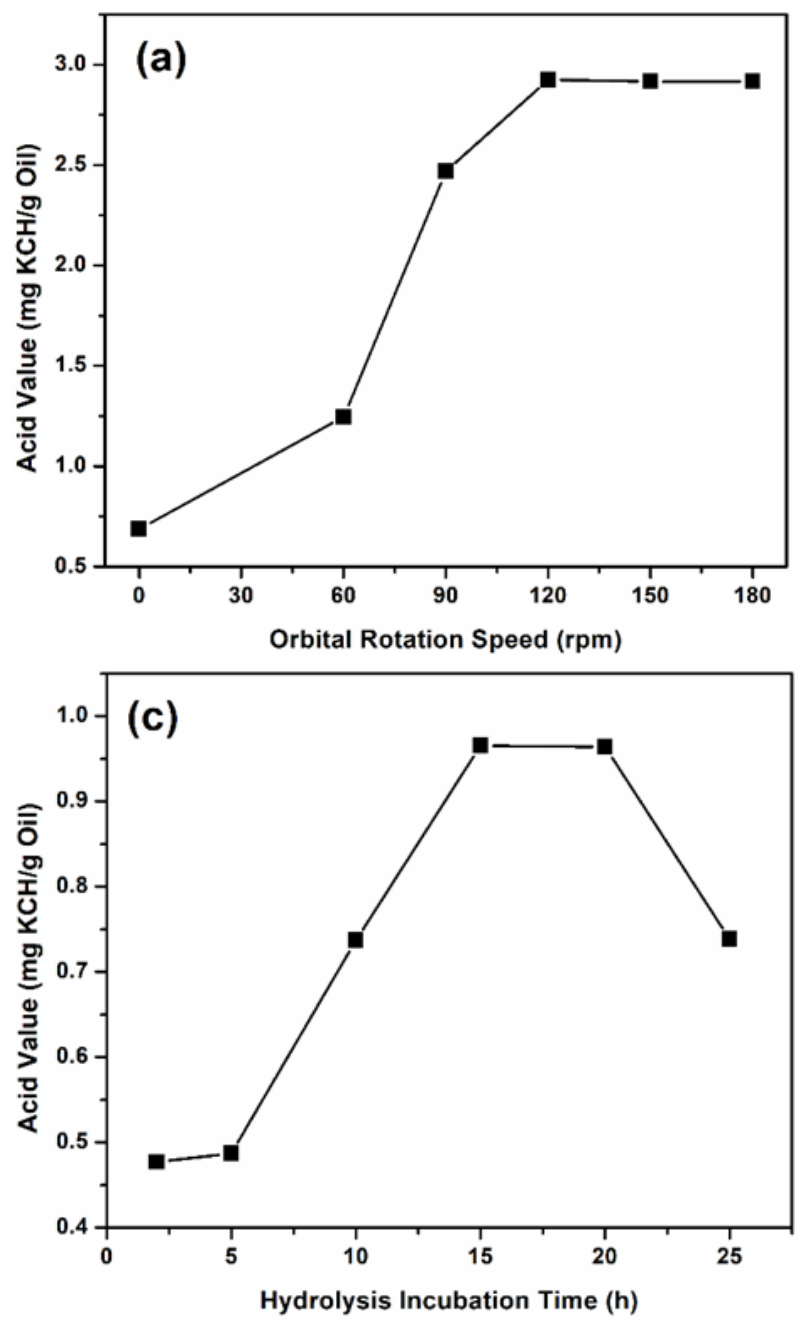
ter hydrolysis reaction, the acid value of fatty

\section{Result and Discussion}

\subsection{Single Factor Analysis}

Figure 1a shows the effect of orbital rotation on the acid value of coconut oil hydrolysis. As exhibited in the figure, the acid value increased significantly by increasing rotation speed from 50 to $150 \mathrm{rpm}$. Moreover, at the orbital rotation speed of $180 \mathrm{rpm}$, the acid value was constant. These results indicated that the mass transfer barrier would increase when there was no effect of the mass transfer diffusion at high rotation speed [27]. These results match those observed in earlier studies on the study of citronellyl acetate esterification using Burkholderia cepacia immobilized lipase (BCL) $[28,29]$. They revealed that the external mass transfer limit at various rotation speed gave a significant impact for chemical or enzymatic reaction.
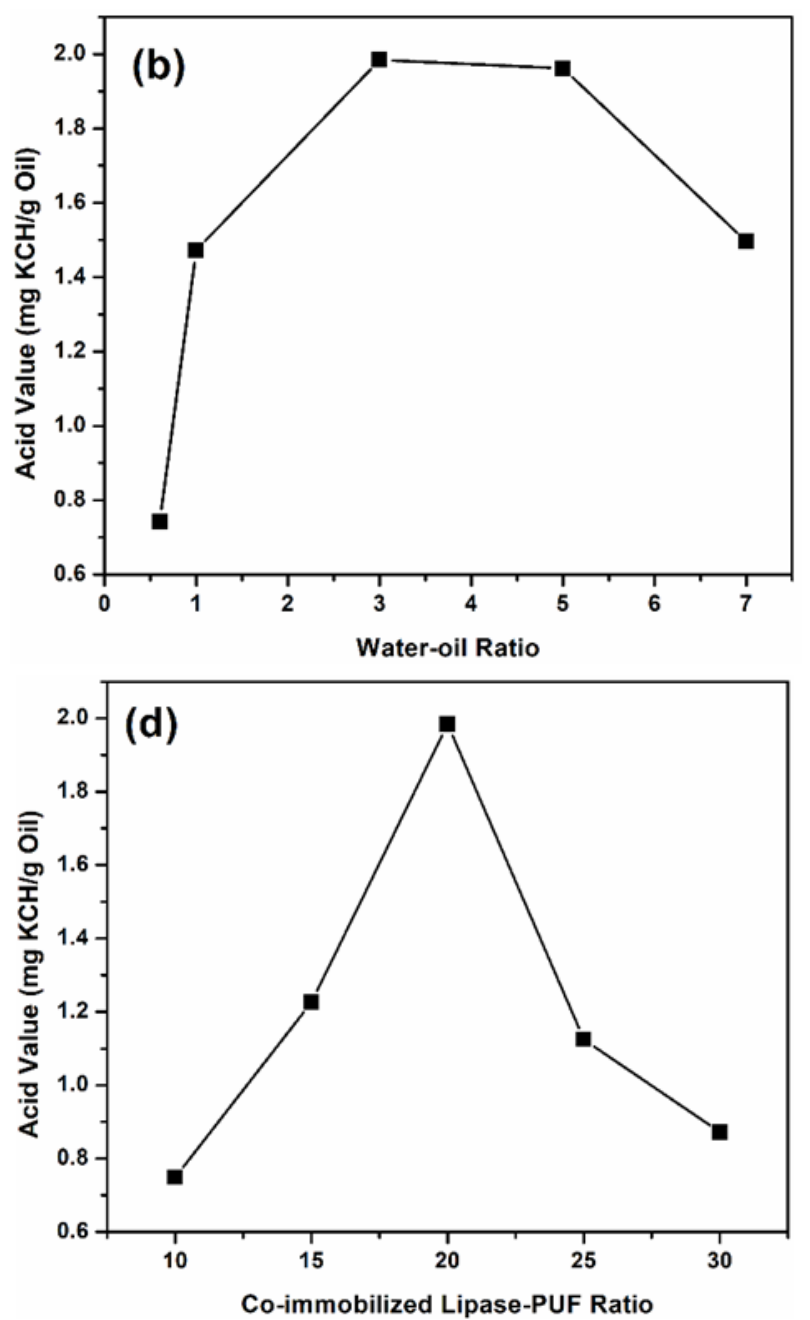

Figure 1. The effect of (a) orbital rotation speed, (b) water-oil ratio, (c) incubation time, and (d) coimmobilized-PUF ratio on the acid value of coconut oil hydrolysis reaction. 
The effect of water-oil ratio on the acid value of hydrolysis was presented in Figure $1 b$. The figure demonstrates that the acid value escalated by increasing water-oil ratio from $0.6: 1$ to $3: 1$, followed by slight decreased at ratio of $5: 1$, and finally decreased remarkably at $7: 1$. From the results, the optimum water- oil ratio was obtained at ratio of $3: 1(\mathrm{w} / \mathrm{w})$, which has the same tendency as some previous studies $[1,30]$. Increasing water-oil ratio was proportional as increasing the acid value which related to the amount of FFA as the product of hydrolysis. This phenomenon may due to enlargement of the interfacial area at the higher ratio. The high amount of water in the hydrolysis reaction causes equilibrium shifting to the product side during the process. Nevertheless, adding continuously the water would initiate diminishing the lipase enzyme activity. In the water-oil ratio greater than 5:1, lipase competes with FFA produced to occupy the interfacial region. Hence the contact between lipase and oil becomes smaller [31].

The effect of hydrolysis incubation time was illustrated in Figure 1c. The acid value increased considerably to a maximum value at 15 $\mathrm{h}$ of hydrolysis, then slight decreased after 20 $\mathrm{h}$, and lastly declined notably following $25 \mathrm{~h}$. The increase of acid value indicates a high interaction between triglycerides and lipases as increasing reaction time. FFA produced acts as inhibitors that block the interaction between oil and enzyme so that the resulting FFA became less [9].
The effect of co-immobilized-PUF ratio is shown in Figure 1d. There was a significant increase of acid value as an increase coimmobilized lipase-PUF ratio from 10:1 to 20:1. Co-immobilized consisted of lecithin, gelatin, and PEG that has the properties as a surfactant/emulsifier and $\mathrm{MgCl}_{2}$ as a cofactor. The surfactants and lipases which both work on the interfacial surface requires proper comparison with the PUF matrix leading to the excellent role of the active site of enzymes. Lecithin and gelatin as thymol emulsifiers are used as food preservation antimicrobials [32]. Thymol as lipophilic is needed as a bacterial inhibitor in milk, carrot juice, ground beef. Gelatin and lecithin as an emulsifier were added so that thymol dispersed well. However, on the coimmobilized lipase: PUF ratio higher than $20: 1$, the acid value extremely decreased. These results revealed that the excessive addition of co-immobilized lipase would result in incomplete binding between the active site and PUF.

\subsection{Second-order Polynomial Model}

The acid value based on the RSM is shown in Table 2. The regression coefficients of intercept, linier, quadratic, and interaction terms of model were calculated using the least square technique and are presented in Table 3. The obtained second-order polynomial equation was found well to represent the experimental data $\left(\mathrm{R}^{2}=0.9390\right)$. The model $p$-value of $0.0018 \mathrm{im}$ ply that the model was statistically significant and show the reliability of the models.

Table 3. The significance of each response variable effect showed by using $F$-value and $p$-value in the non-linier second order model

\begin{tabular}{lcccccc}
\hline & Variables & DF & SS & MS & $F$-value & $p$-value \\
\hline Model & & 9 & 7.48 & 0.83 & 11.98 & 0.0018 \\
Linier effect & $\mathrm{A}$ & 1 & 0.002896 & 0.002896 & 0.042 & 0.8439 \\
& $\mathrm{~B}$ & 1 & 0.35 & 0.35 & 5.1 & 0.0585 \\
Quadratic effect & $\mathrm{C}$ & 1 & 1.21 & 1.21 & 17.49 & 0.0041 \\
& $\mathrm{~A}^{2}$ & 1 & 5.71 & 5.71 & 82.27 & 0.0001 \\
& $\mathrm{~B}^{2}$ & 1 & 0.087 & 0.087 & 1.25 & 0.3008 \\
Interaction effects & $\mathrm{C}^{2}$ & 1 & 0.002001 & 0.002001 & 0.029 & 0.8699 \\
& $\mathrm{AB}$ & 1 & 0.011 & 0.011 & 0.16 & 0.6972 \\
& $\mathrm{AC}$ & 1 & 0.001849 & 0.001849 & 0.027 & 0.8749 \\
& $\mathrm{BC}$ & 1 & 0.00007921 & 0.00007921 & 0.001142 & 0.9740 \\
\hline
\end{tabular}

Note. DF: Degree of freedom, SS: Sum of square, MS: Mean of square. The bold letter denoted statistically significantly different at $p=0.05$ 


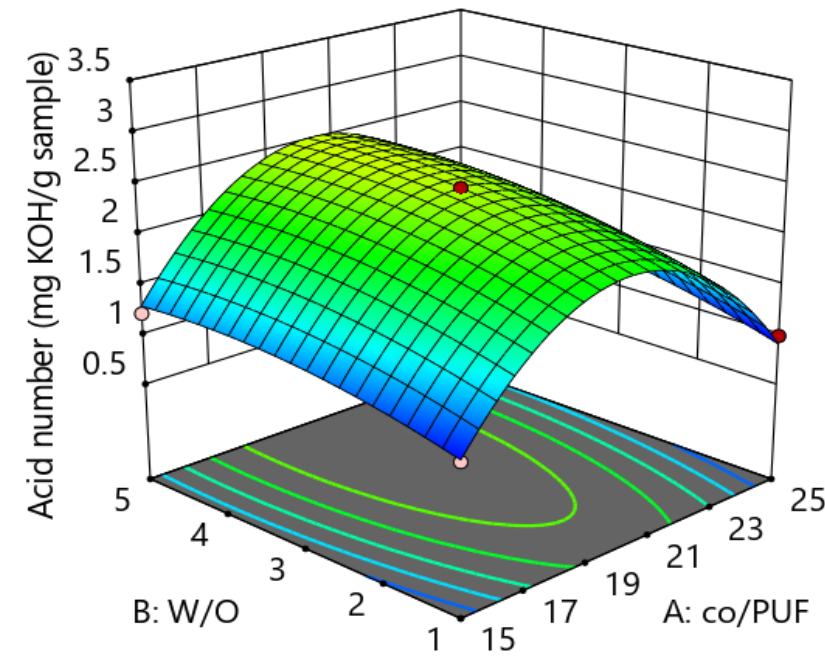

(a)

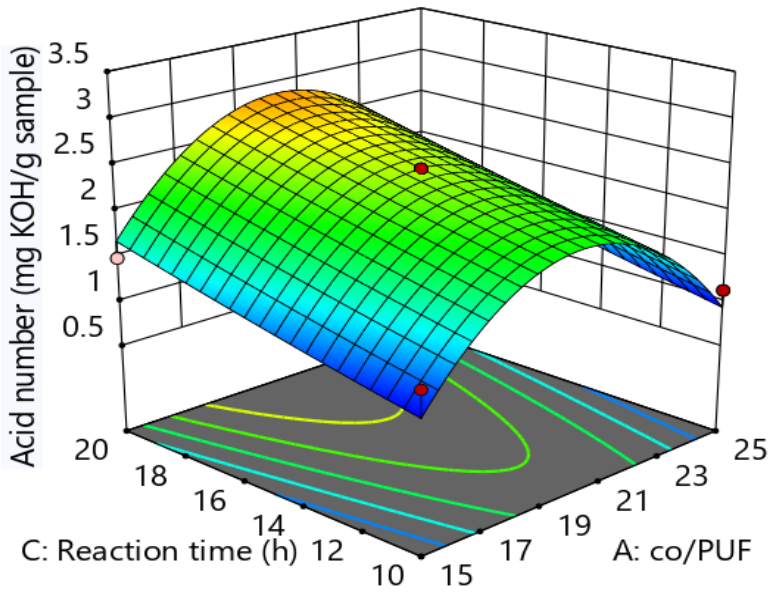

(b)

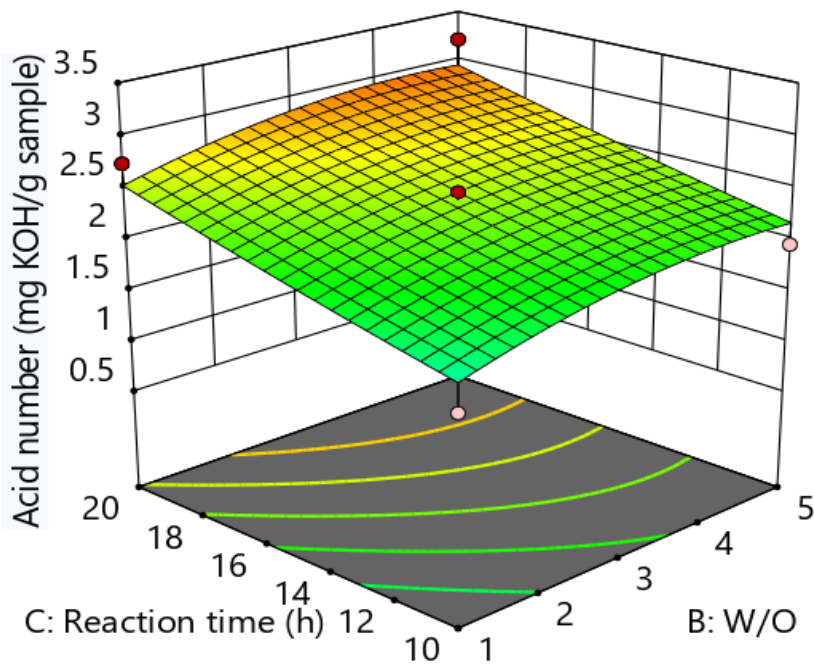

(c)

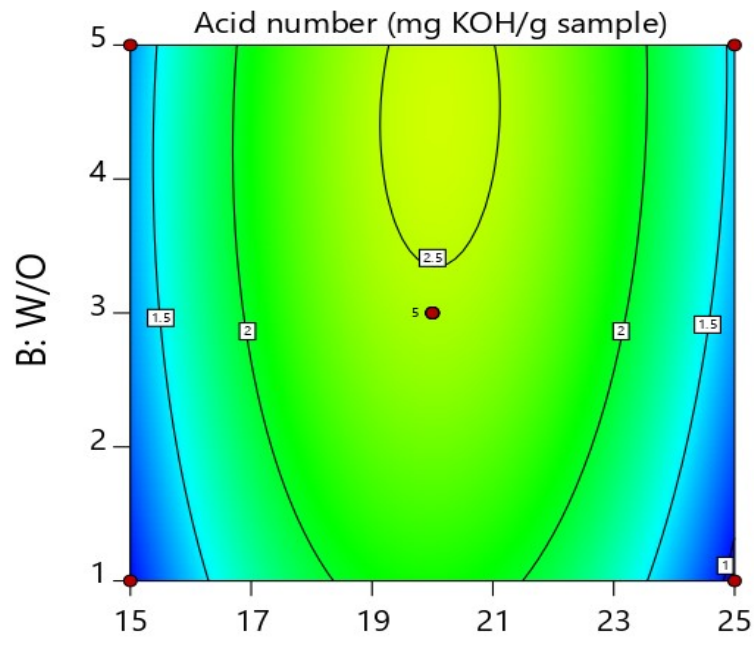

A: co/PUF

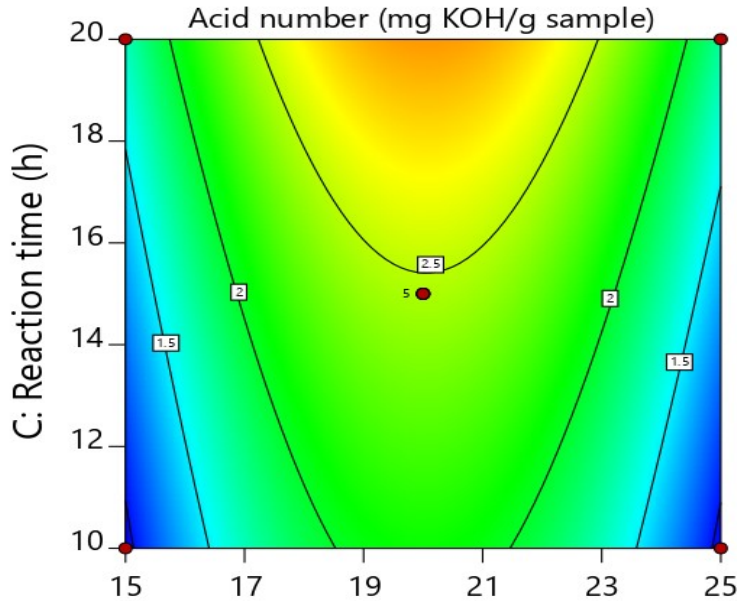

A: co/PUF

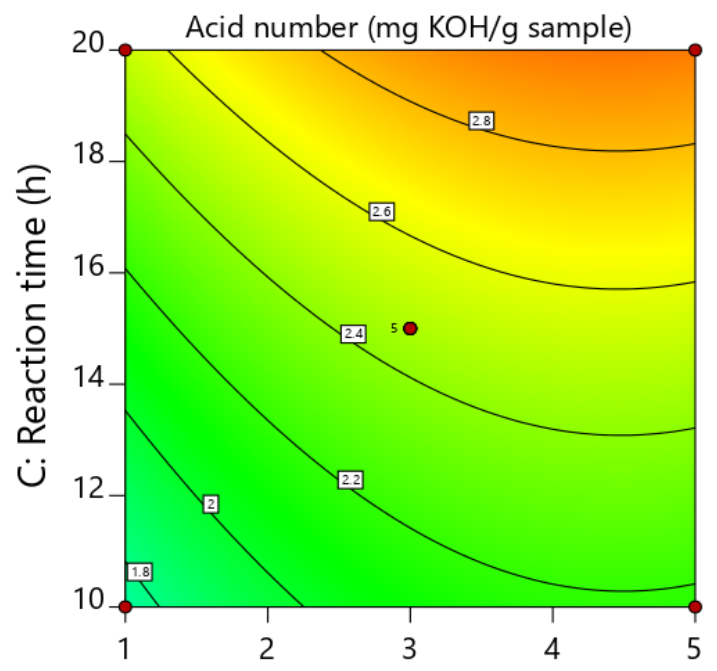

B: W/O

Figure 2. Surface and contour plot of (a) fixed hydrolysis incubation time of $15 \mathrm{~h}$, (b) fixed water-oil ratio $=3: 1$, and (c) fixed co-immobilized lipase:PUF ratio $=20: 1$ 
Acid value $=-17.2889+1.83776 A+0.2201 B+0.035865 C$ $+0.00534 A B+0.00086 A C-0.000445 B C$ $-0.046572 A^{2}-0.003585 B^{2}+0.000872 C^{2}$

The $p$-values were used as a tool to check the significance of each coefficient, which in turn may indicate the pattern of the interactions between the variables. As shown in Table 3 , the linear coefficients $(\mathrm{A}, \mathrm{B})$, quadratic coefficients $\left(\mathrm{B}^{2}, \mathrm{C}^{2}\right)$ and interaction coefficients $(\mathrm{AB}$, $\mathrm{AC}, \mathrm{BC})$ had no significant effect $(p>0.05)$. On the other hand, the effect of linier $\mathrm{C}$ and quadratic $\mathrm{A}^{2}$ was highly significant $(p<<0.05)$. The predicted values calculated from Eq.(5) were in very good agreement with the experimental values, as shown in Table 2 . Hence, this quadratic model is well suited for this experimental set up.

In order to compare the predicted result with the practical value, retrial experiment was performed using some different hydrolysis condition. The values obtained from real experiments demonstrated the validity of the RSM model, since there were no significant differences of residue (See Table 4). The strong correlation between the real and the predicted results confirmed that the response model was

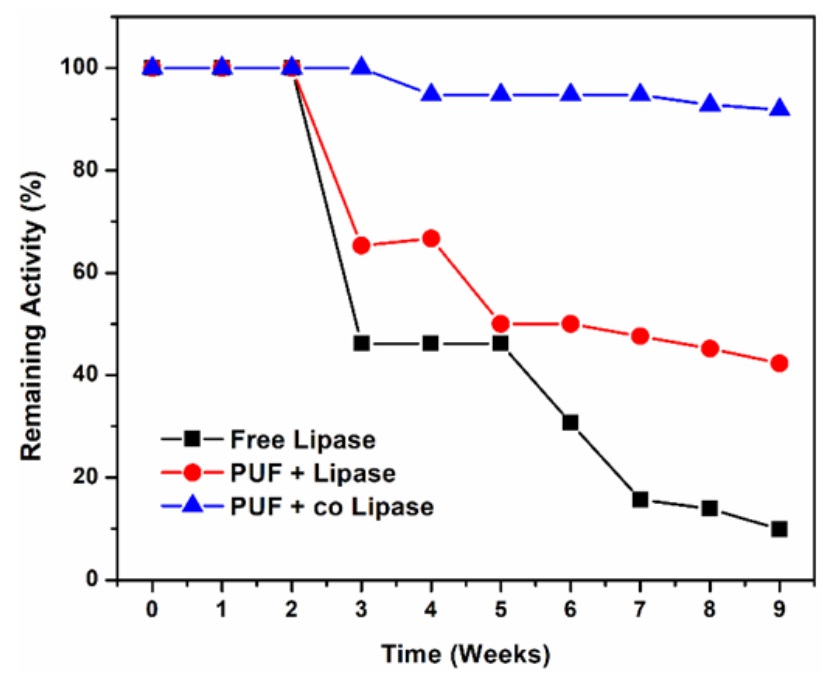

Figure 3. Time course of remaining enzyme activity (\%) on free and immobilized lipase at the storage temperature of $4^{\circ} \mathrm{C}$ adequate to reflect the expected hydrolysis condition.

\subsection{Response Surface Methodology Analysis}

Lipase is an enzyme that works in the interfacial area of water and oil in a two-phase system. Lipase acts to cut the acyl group ( $\mathrm{RCOO}$-) in triglycerides and hydrogen ions $\left(\mathrm{H}^{+}\right)$in water to form free fatty acids $(\mathrm{RCOOH})$. Figure $2 \mathrm{a}$ presents the effect of water-oil ratio, and coimmobilized lipase: PUF ratio towards the acid value at fixed hydrolysis incubation time of $15 \mathrm{~h}$. The acid value is typically decreased from the water-oil ratio of $1: 1$ to $5: 1$. The steep curvature in water: oil ratio behavior demonstrated the response of acid value was very rapid to these factors. The results of this study have the same tendency as earlier work that the increase in the water-oil ratio was proportional to the increase in the percentage of FFA yield [31]. This result may occur because of at the higher water ratio, the interfacial area of water oil was also getting greater. This high interfacial area caused the equilibrium shift to the product of hydrolysis. On the contrary, in low interfacial conditions, the lower area will cause a decrease in the effective of the lipase enzyme activity [31].

The contour plot in Figure $2 \mathrm{~b}$ shows that the acid value increased remarkably from Co: PUF ratio of 15 to 20 , then decreased significantly on Co: PUF ratio of 25 . Pretreatment using the organic polymer as initial wetting could increase the amount of the loaded enzyme, as seen on the Co: PUF ratio of 20 [33]. Coimmobilized consisted of blending of surfactant, lecithin, gelatin with PEG as crosslinker and $\mathrm{MgCl}_{2}$ as a cofactor. The blending of lecithin and gelatin can reduce the size of the dispersed particles significantly. This condition allows for more bonding with the active site of lipase, leading to an increase in the conversion of hydrolysis reactions to fatty acids [32,34,35]. The combination of these ingredients can also take a role as a membrane for immobilization of lipase [23]. However, the decrease in acid value above co: PUF ratio of 20 may due to the

Table 4. Predicted and experimental values of responses at some hydrolysis condition

\begin{tabular}{cccccccc}
\hline \multirow{2}{*}{ Run } & \multicolumn{3}{c}{ Actual variable } & & \multicolumn{3}{c}{ Acid value (mg KOH/g oil) } \\
\cline { 2 - 3 } & $\mathrm{A}(\mathrm{co} / \mathrm{PUF})$ & $\mathrm{B}(\mathrm{W} / \mathrm{O})$ & $\mathrm{C}(\mathrm{h})$ & & Experimental & Predicted & Residue \\
\hline 1 & 15 & 5 & 20 & & 1.6012 & 1.6832 & -0.0820 \\
2 & 20 & 3 & 20 & & 2.9293 & 2.8795 & -0.0503 \\
3 & 25 & 3 & 15 & & 1.2388 & 1.3224 & -0.0836 \\
4 & 25 & 5 & 10 & & 1.1115 & 1.0580 & 0.0535 \\
\hline
\end{tabular}


ability of PUF to adsorb Co-immobilized has been saturated. Furthermore, $\mathrm{MgCl}_{2}$ which was not adsorbed by PUF would become an inhibitor because it will compete with enzymes [36].

Figure $2 \mathrm{~b}$ demonstrates response surface and the contour plot for hydrolysis of coconut oil by varying co-immobilized: PUF ratio and hydrolysis incubation time at a fixed water-oil ratio of 3. In the contour plot shown in Figure $2 \mathrm{~b}$, the acid value escalated significantly from the reaction time of 10 to $20 \mathrm{~h}$. Prolong the reaction time gave a significant curvature effect on the speed of the hydrolytic lipase reaction yielding the increase of FFA production. The reaction time was limited to $20 \mathrm{~h}$ which intend to prevent FFA produced did not play a role as an inhibitor that can block the interaction between oil and water (see Figure 1c) [30].

Figures 2c shows the effect of the water-oil ratio and hydrolysis incubation time in the hydrolysis process at a fixed co immobilized lipase: PUF ratio of 20 . The acid value increased evidently as the increasing of water-oil ratio and nearly reached a maximum value at the highest hydrolysis incubation time. It can be seen that the maximum acid value of FFA obtained at the water-oil ratio and hydrolysis incubation time was 4.4 and $20 \mathrm{~h}$, respectively.

From $F$-value in Table 3, the significant parameter was determined. It can be seen that linear effect of hydrolysis incubation time and quadratic effect of co-immobilized lipase: PUF ratio was the significant parameter. The optimal hydrolysis condition was achieved at co immobilized: PUF ratio, water: oil ratio, and hydrolysis incubation time of $20.17,4.45$, and 20 $\mathrm{h}$, respectively. At optimized condition, the pre- dicted acid value of FFA was $3.21 \mathrm{mg} \mathrm{KOH} / \mathrm{g}$ sample oil.

\subsection{Storage Stability of Co-immobilized Lipases}

The storage stability of the enzyme was carried out by examining the enzyme activity of free lipase, PUF-lipase, and PUF-coimmobilized lipase at a storage temperature of $4{ }^{\circ} \mathrm{C}$ for 9 weeks. As presented in Figure 3, the remaining activity of $100 \%$ of the three immobilization methods was still stable until the two weeks. However, after the 3rd week, there was a decrease in stability in free lipase and PUF-lipase to $46.15 \%$ and $65.31 \%$, respectively. At week 4, the stability of PUF-co-immobilized

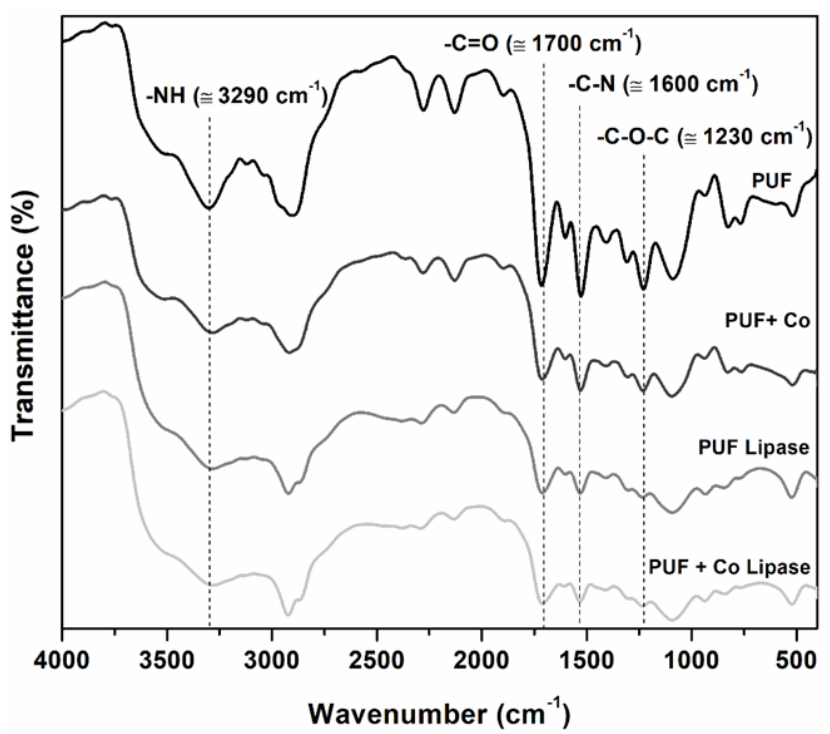

Figure 5. FTIR spectra of (a) PUF, (b) PUF-Co, (c) immobilized lipase on PUF and (d) coimmobilized lipase on PUF.

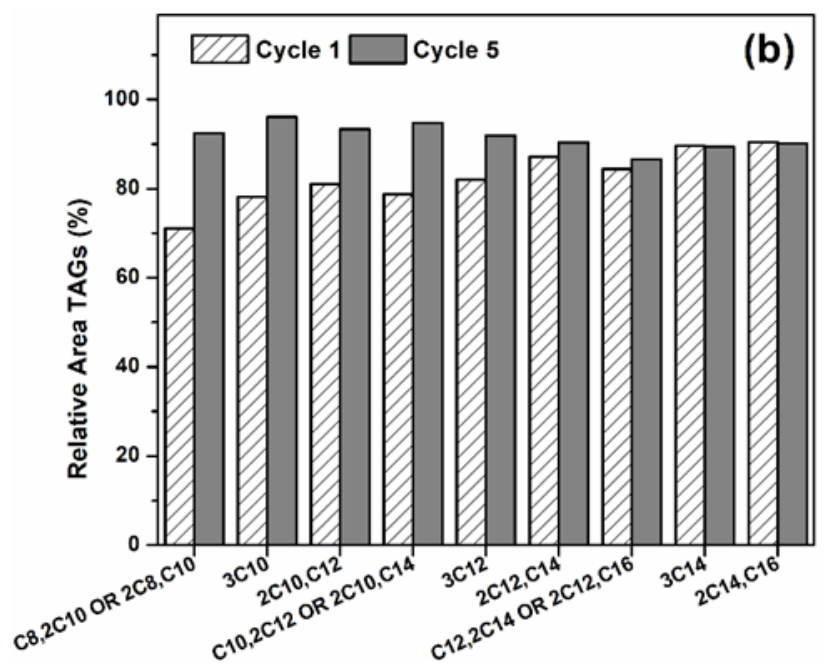

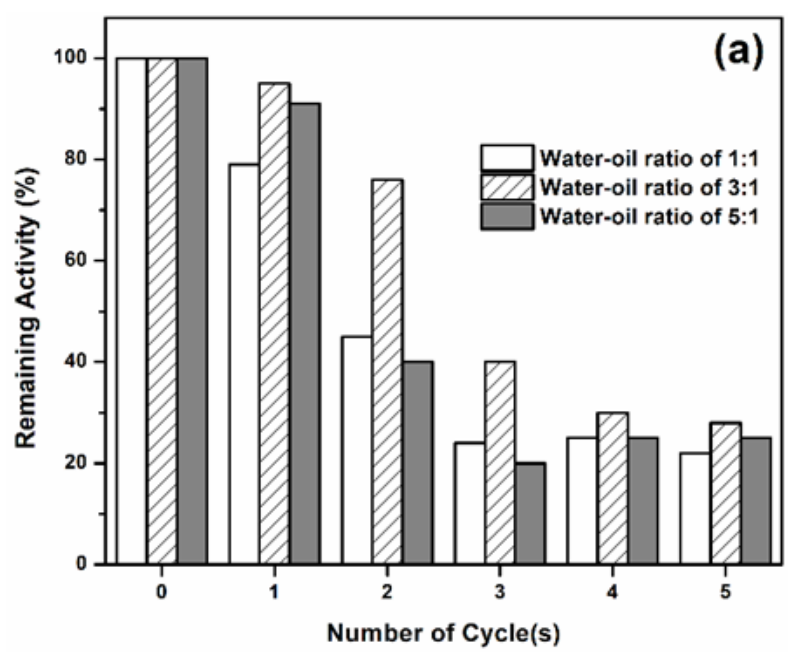

Figure 4. Plot of (a) remaining activity on reuse of Immobilized Lipases and (b) relative percentages of residual TAGs to fatty acids in various uses of immobilization of lipase for coconut oil hydrolysis. 
lipase began to decline to $94.73 \%$. After 4 weeks, the enzyme stability by all methods have decreased, especially free lipase. Until the storage time of 9 weeks, the stability of free lipase, PUF-lipase, and PUF-co-immobilizedlipase decreased to $9.89 \%, 42.3 \%$, and $91.88 \%$, respectively. The same phenomenon was found on the esterification reaction using PUF as a matrix for lipase immobilization through polyethyleneimine (PEI) coating and the addition of glutaraldehyde (GA) [16]. At an incubation condition of $50{ }^{\circ} \mathrm{C}$ for $30 \mathrm{~min}$, remaining activity of free lipase, immobilized lipase on PUF, and immobilized lipase on PEI-coated PUF was $0 \%$, $20 \%$, and $50 \%$, respectively. Great remaining activity from lipase immobilization due to covalent bonds that can increase storage stability $[4,12,16]$. The addition of matrix material in this study namely gelatin, lecithin, $\mathrm{PEG}, \mathrm{MgCl}_{2}$ can act as spacers to extend and strengthen covalent bonds between matrix and lipase. The enzyme molecules that have been activated
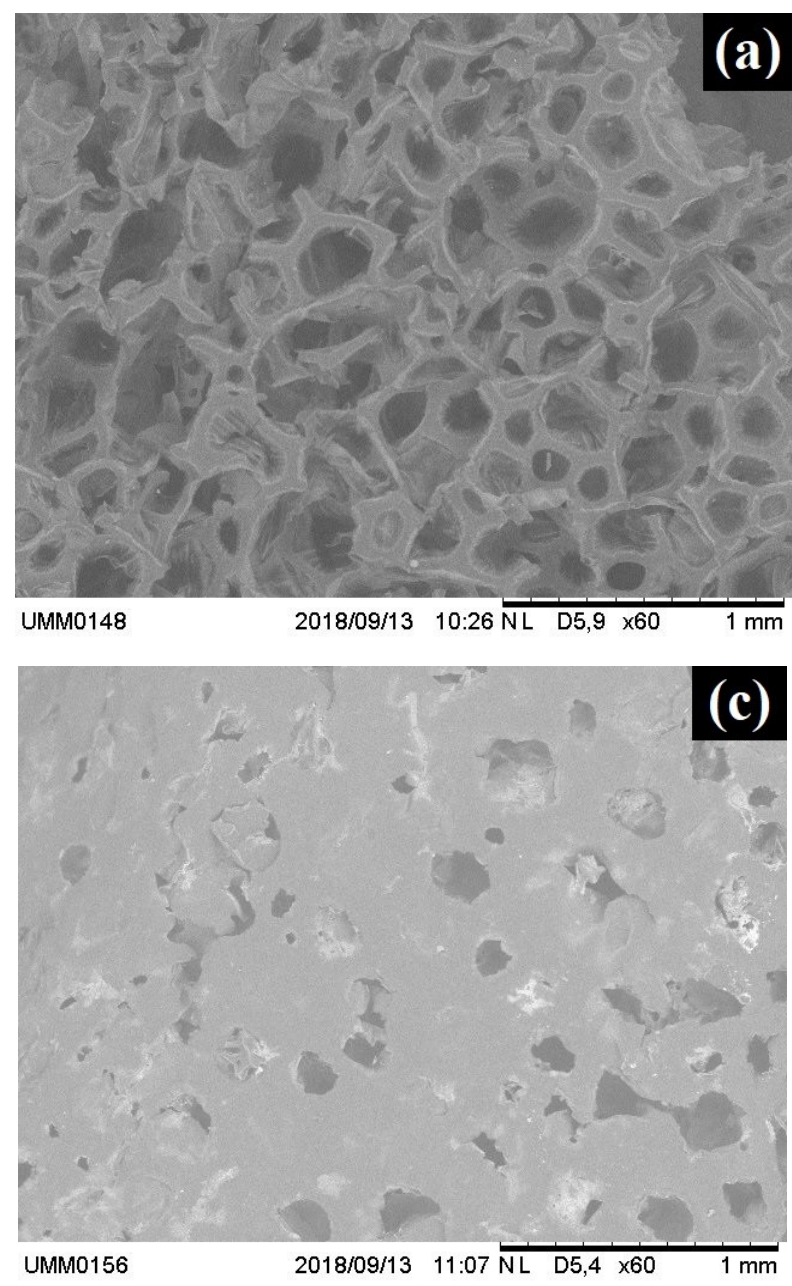

with the addition of co-immobilized are therefore bound to be more stable to the PUF matrix $[4,16]$.

\subsection{Reusability Studies}

One of the advantages of the immobilization method is the reusability of enzymes leading to minimizing operational costs. Figure $4 \mathrm{a}$ depicts the remaining activity of the reuse lipases $M$. miehei on the various water-oil ratio in the hydrolysis of coconut oil into FFA. After 3 cycles, the activity remained about $50 \%$ of the initial activity. Similar results were shown by $[15,37,38]$. The acid values of this study were relatively low compared to literature which uses commercial immobilized lipase with a remaining activity of $50 \%$ after 5 times cycles. A water-oil ratio of $3: 1$ and 5:1 have a relatively better ability than 1:1. However, after 4, 5, and 6 times cycles, there was a significant decrease in remaining activities up to 22,28 , and $25 \%$, respectively.
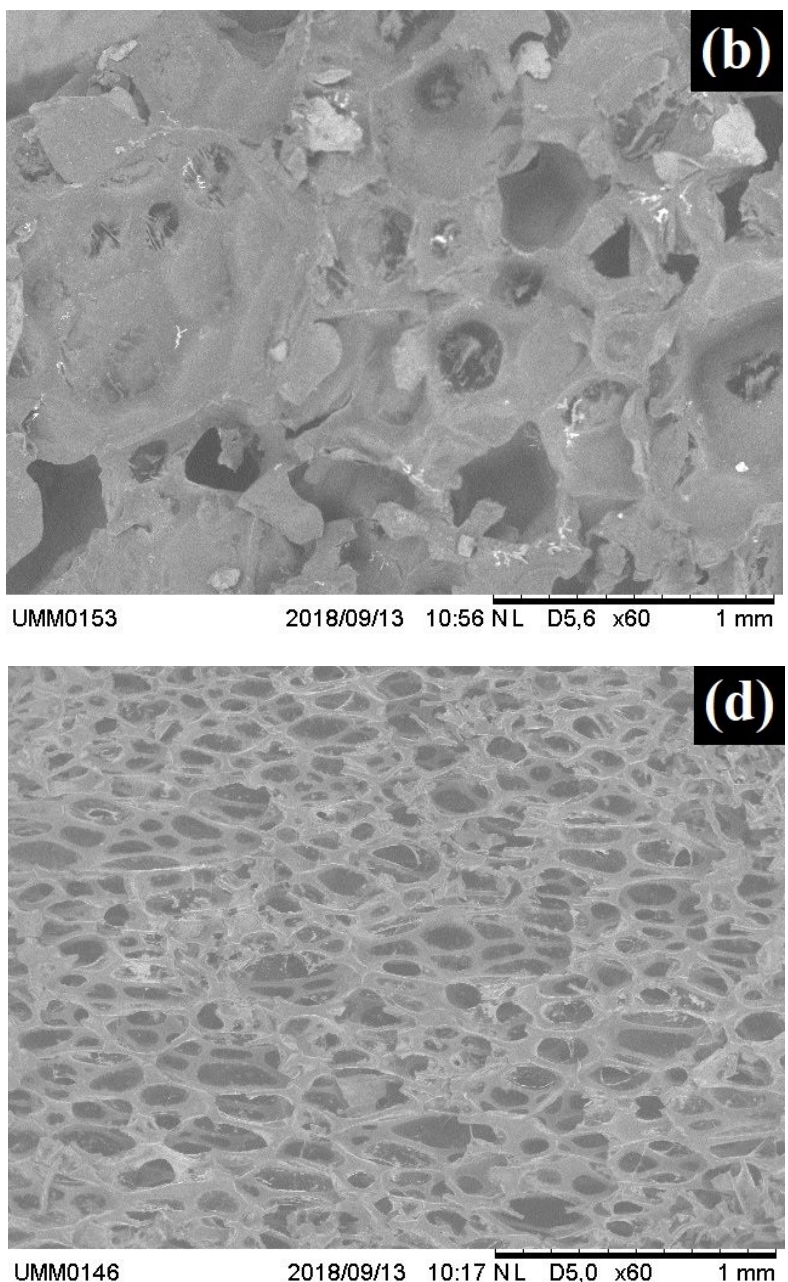

Figure 6. Scanning electron micrograph of a) PUF, b) PUF-Co immobilized, c) PUF-lipase, and d) co-immobilized lipase on PUF 
The coconut oil contains TGAs of $92 \%$, fatty acids as lauric acid (C12) of $0.1-3.5 \%$, and sterols tocol of $0.5-1.5 \%$. TGAs components may consist of a combination of 3 fatty acid molecules, including a combination of $\mathrm{C} 8,2 \mathrm{C} 10$ or 2 C8, C10; $3 \mathrm{C} 12$, and others [39]. In the initial condition, the combination of the TAGS components was $100 \%$ (see Figure $4 \mathrm{~b}$ ). In the cycle of 1 and 5 , the amount of TAGs was less than $100 \%$, which means TAGs was converted to FFA. For example, the initial TAGs components of $\mathrm{C} 8,2 \mathrm{C} 10$ or $2 \mathrm{C} 8, \mathrm{C} 10$, after hydrolysis in cycle 1 , and cycle 5 were $100 \%, 71.07 \%$, and $92.09 \%$, respectively. While the initial TAGs component of $3 \mathrm{C} 12$, after hydrolysis in the cycle 1 , and cycle 5 , were $100 \%, 82.07 \%$, and $91.85 \%$, respectively. The same trend was shown by other constituent components of TAGs. This phenomenon shows that in the cycle 1, hydrolysis using immobilized lipase on PUF could convert TAGs higher than cycle 5 . These results were confirmed by remaining activity of cycle 1 which was higher than cycle 5 (Figure 4 (a)).

3.6 Characterization of Native PUF and Its Variation of Immobilization Techniques

\subsubsection{FTIR analysis}

In Figure 5, spectrum of native PUF were illustrated as the peaks of amide group $-\mathrm{NH}( \pm$ $\left.3290 \mathrm{~cm}^{-1}\right)$, carbonyl urethane group $-\mathrm{C}=\mathrm{O}( \pm$ $\left.1700 \mathrm{~cm}^{-1}\right)$, carbamate group $-\mathrm{CN}\left( \pm 1600 \mathrm{~cm}^{-1}\right)$ and $-\mathrm{COC}\left( \pm 1230 \mathrm{~cm}^{-1}\right)[40,41]$. The addition of co-immobilized agents affected the intensity of the peaks. There were changes of native PUF intensity. The co-immobilized which consist of gelatin, lecithin, $\mathrm{PEG}$, and $\mathrm{MgCl}_{2}$ contains a lot of amide, and carbonyl group. Whereas the lipases which are suspended from amino acids have primary amide $\mathrm{N}-\mathrm{H}$ regions at wavelengths of around $1650 \mathrm{~cm}^{-1}$ and $-\mathrm{C}=\mathrm{O}[41,42]$. Because of the immobilization of lipase on PUF through coating these materials, the native PUF intensity in the four wavelengths become weaker. This phenomenon presented the real effect of co-immobilized and lipase coating on native PUF.

\subsubsection{SEM analysis}

The morphological structures of native PUF, PUF-Co immobilized, immobilized lipase on PUF and co-lipase immobilized on PUF are shown in Figure 6. As presented in Figure 6, the addition of lipase to PUF demonstrated a smoother surface than native PUF. This phenomenon indicates that the lipase, through its covalent bond, can attach to the porous PUF surface. On the addition of co-immobilized lipase (see Figure 6d), there was an agglomeration of these materials. This phenomenon was proven by the measurement of the average diameter of co-immobilized lipase on PUF (104 $\mu \mathrm{m})$ which smaller than native PUF $(221 \mu \mathrm{m})$. Moreover, this result reveals that lipase attached to the surface of PUF which has been coated with co-immobilized. The SEM figures of this study is in line with the previous work on the immobilization of lipase C. Antarctica $B$ using PUF for geranyl propionate and ethyl oleate synthesis [43]. The SEM graph of PUF immobilized lipase $Y$. lipolytica via polyethyleneimine coating and glutaraldehyde coupling was also smoother than the native PUF [16].

\section{Conclusions}

The co-immobilized lipase on PUF can be used effectively to hydrolyze coconut oil to FFA. The optimum condition of hydrolysis reaction through RSM was obtained on the coimmobilized lipase: PUF ratio, water-oil ratio and hydrolysis incubation time of $20.17,4.45$, and $20 \mathrm{~h}$, respectively. In the optimum condition, co-immobilized lipase can be reused for 5 reactions and increase storage stability at $4{ }^{\circ} \mathrm{C}$ for 9 weeks. Remaining activity after 5 times hydrolysis from co-immobilized lipase, immobilized lipase, and free lipase was $91.88 \%, 42.3 \%$, and $9.89 \%$, respectively. The optimal condition resulted in a FFA of $3.2107 \mathrm{mg} \mathrm{KOH/g}$ oilsample.

\section{Acknowledgments}

The authors thank the Directorate General of Resources for Science, Technology \& Higher Education, Ministry of Research, Technology and Higher Education of Republic Indonesia for financial support (205/SP2H/LT/ DRPM/III/2016) of this study.

\section{References}

[1] Sharma, A., Chaurasia, S.P., Dalai, A.K. (2013). Enzymatic hydrolysis of cod liver oil for the fatty acids production. Catal. Today. 207: 93-100. doi:10.1016/j.cattod.2012.05.006.

[2] Murty, V.R., Bhat, J., Muniswaran, P.K.A. (2002). Hydrolysis of oils by using immobilized lipase enzyme: A review. Biotechnol. Bioprocess Eng. 7: 57-66. doi: 10.1007/BF02935881. 
[3] Mohammadi, M., Habibi, Z., Dezvarei, S., Yousefi, M., Ashjari, M. (2015). Selective enrichment of polyunsaturated fatty acids by hydrolysis of fish oil using immobilized and stabilized Rhizomucor miehei lipase preparations. Food Bioprod. Process. 94: 414-421. doi:10.1016/j.fbp.2014.05.007.

[4] Cao, L. (2005). Carrier-bound Immobilized Enzymes: Principles, Application and Design, WILEY-VCH Verlag GmbH \& Co. KGaA, Weinheim. doi:10.1201/9783527607082.

[5] Taqieddin, E., Amiji, M. (2004). Enzyme immobilization in novel alginate-chitosan coreshell microcapsules. Biomaterials. 25: 19371945. doi:10.1016/j.biomaterials.2003.08.034.

[6] Prastowo, I., Hidayat, C., Hastuti, P. (2015). Production of Oleic Acid Ethyl Ester catalyzed by crude rice bran (Oryza sativa) lipase in a modified fed-batch system: A problem and its solution, Bull. Chem. React. Eng. Catal. 10: 230-236. doi:10.9767/bcrec.10.3.8511.230-236.

[7] Saleem, M., Rashid, M.H., Jabbar, A., Perveen, R., Khalid, A.M., Rajoka, M.I. (2005). Kinetic and thermodynamic properties of an immobilized endoglucanase from Arachniotus citrinus. Process Biochem. 40: 849-855. doi:10.1016/j.procbio.2004.02.026.

[8] Yücel, Y. (2012). Optimization of immobilization conditions of Thermomyces lanuginosus lipase on olive pomace powder using response surface methodology, Biocatal. Agric. Biotechnol. 1: 39-44. doi:10.1016/j.bcab.2011.08.009.

[9] Li, Y., Wang, Z., Xu, X., Jin, L. (2015). A Caalginate particle co-immobilized with Phanerochaete chrysosporium cells and the combined cross-linked enzyme aggregates from Trametes versicolor. Bioresour. Technol. 198: 464-469. doi:10.1016/j.biortech.2015.09.032.

[10] Pires-Cabral, P., da Fonseca, M.M.R., Ferreira-Dias, S. (2009). Synthesis of ethyl butyrate in organic media catalyzed by Candida rugosa lipase immobilized in polyurethane foams: A kinetic study. Biochem. Eng. J. 43: 327-332. doi:10.1016/j.bej.2008.11.002.

[11] Hilmanto, H., Hidayat, C., Hastuti, P. (2016). Surface modification of macroporous matrix for immobilization of lipase for fructose oleic ester synthesis. Bull. Chem. React. Eng. Catal. 11: 339-345.

doi:10.9767/bcrec.11.3.573.339-345.

[12] El-Ghaffar, M.A.A., Hashem, M.S. (2010). Chitosan and its amino acids condensation adducts as reactive natural polymer supports for cellulase immobilization. Carbohydr. Polym. 81: 507-516.

doi:10.1016/j.carbpol.2010.02.025.

[13] Li, C., Zhang, G., Liu, N., Liu, L. (2015). Preparation and properties of Rhizopus Oryzae li- pase immobilized using an adsorptioncrosslinking method. Int. J. Food Prop. 19: 1776-1785.

doi:10.1080/10942912.2015.1107732.

[14] Dizge, N., Keskinler, B. (2008). Enzymatic production of biodiesel from canola oil using immobilized lipase. Biomass and Bioenergy. 32: $1274-1278$.

doi:10.1016/j.biombioe.2008.03.005.

[15] Pires-Cabral, P., da Fonseca, M.M.R., Ferreira-Dias, S. (2010). Esterification activity and operational stability of Candida rugosa lipase immobilized in polyurethane foams in the production of ethyl butyrate. Biochem. Eng. J. 48: 246-252. doi:10.1016/j.bej.2009.10.021.

[16] Cui, C., Tao, Y., Li, L., Chen, B., Tan, T. (2013). Improving the activity and stability of Yarrowia lipolytica lipase Lip2 by immobilization on polyethyleneimine-coated polyurethane foam. J. Mol. Catal. B Enzym. 91: 5966. doi:10.1016/j.molcatb.2013.03.001.

[17] Akoz, E., Sayin, S., Kaplan, S., Yilmaz, M. (2015). Improvement of catalytic activity of lipase in the presence of calix[4]arene valeric acid or hydrazine derivative, Bioprocess Biosyst. Eng. 38: 595-604. doi:10.1007/s00449014-1299-x.

[18] Cabrera-Padilla, R.Y., Melo, E.B., Pereira, M.M., Figueiredo, R.T., Fricks, A.T., Franceschi, E., Lima, Á.S., Silva, D.P., Soares, C.M.F. (2015). Use of ionic liquids as additives for the immobilization of lipase from Bacillus sp. J. Chem. Technol. Biotechnol. 90: 1308-1316. doi:10.1002/jctb.4438.

[19] Arnold, G., Schuldt, S., Schneider, Y., Friedrichs, J., Babick, F., Werner, C., Rohm, H. (2013). The impact of lecithin on rheology, sedimentation and particle interactions in oilbased dispersions. Colloids Surfaces A Physicochem. Eng. Asp. 418: 147-156. doi:10.1016/j.colsurfa.2012.11.006.

[20] Xuan, X.Y., Cheng, Y.L., Acosta, E. (2012). Lecithin-linker microemulsion gelatin gels for extended drug delivery. Pharmaceutics. 4: 104-129. doi:10.3390/pharmaceutics4010104.

[21] Wang, P., Fan, X., Cui, L., Wang, Q., Zhou, A. (2008). Decolorization of reactive dyes by laccase immobilized in alginate/gelatin blent with PEG. J. Environ. Sci. 20: 1519-1522. doi:10.1016/S1001-0742(08)62559-0.

[22] Awang, R., Ghazuli, M.R., Basri, M. (2007). Immobilization of lipase from Candida rugosa on palm-basedpolyurethane foam as a support material. American J. Biochem. Biotechnol. 3: 163-166.

[23] Yin, C., Liu, T., Tan, T. (2006). Synthesis of vitamin A esters by immobilized Candida sp. 
lipase in organic media. Chinese J. Chem. Eng. 14: 81-86. doi:10.1016/S10049541(06)60041-4.

[24] Abbas, H., Comeau, L. (2003). Aroma synthesis by immobilized lipase from Mucor sp. Enzyme Microb. Technol. 32: 589-595. doi:10.1016/S0141-0229(03)00022-X.

[25] Ferraz, L.I.R., Possebom, G., Alvez, E.V., Cansian, R.L., Paroul, N., de Oliveira, D., Treichel, H. (2015). Application of home-made lipase in the production of geranyl propionate by esterification of geraniol and propionic acid in solvent-free system. Biocatal. Agric. Biotechnol. 4: 44-48.

doi:10.1016/j.bcab.2014.07.003.

[26] Lopes, D.B., Fraga, L.P., Fleuri, L.F., Macedo, G.A. (2011). Lipase and Esterase- to What Extent Can This Classification be Applied Accurately? Food Sci. Technol. 31(3): 608-613 (doi: 10.1590/S0101-20612011000300009)

[27] Yadav, G.D., Pawar, S.V. (2012). Synergism between microwave irradiation and enzyme catalysis in transesterification of ethyl-3phenylpropanoate with n-butanol. Bioresour. Technol. 109: 1-6.

doi:10.1016/j.biortech.2012.01.030.

[28] Badgujar, K.C., Bhanage, B.M. (2014). Application of lipase immobilized on the biocompatible ternary blend polymer matrix for synthesis of citronellyl acetate in non-aqueous media: Kinetic modelling study. Enzyme Microb. Technol. 57:16-25.

doi:10.1016/j.enzmictec.2014.01.006.

[29] Hung, T.C., Giridhar, R., Chiou, S.H., Wu, W.T. (2003). Binary immobilization of Candida rugosa lipase on chitosan. J. Mol. Catal. B Enzym. 26: 69-78. doi:10.1016/S13811177(03)00167-X.

[30] Khaskheli, A.A., Talpur, F.N., Ashraf, M.A., Cebeci, A., Jawaid, S., Afridi, H.I. (2015). Monitoring the Rhizopus oryzae lipase catalyzed hydrolysis of castor oil by ATR-FTIR spectroscopy. J. Mol. Catal. B Enzym. 113: 56-61. doi:10.1016/j.molcatb.2015.01.002.

[31] Chowdhury, A., Mitra, D., Biswas, D. (2013). Biolubricant synthesis from waste cooking oil via enzymatic hydrolysis followed by chemical esterification. J. Chem. Technol. Biotechnol. 88: 139-144. doi:10.1002/jctb.3874.

[32] Xue, J., Zhong, Q. (2014). Blending lecithin and gelatin improves the formation of thymol nanodispersions. J. Agric. Food Chem. 62: 2956-2962. doi:10.1021/jf405828s.

[33] Guncheva, M., Tashev, E., Zhiryakova, D., Tosheva, T., Tzokova, N. (2011). Immobilization of lipase from Candida rugosa on novel phosphorous- containing polyurethanes: Application in wax ester synthesis. Process Biochem. 46:923-930.

doi:10.1016/j.procbio.2011.01.002.

[34] Xu, L., Sheybani, N., Ren, S., Bowlin, G.L., Yeudall, W.A., Yang, H. (2015). Semiinterpenetrating network (Sipn) coelectrospun gelatin/insulin fiber formulation for transbuccal insulin delivery. Pharm. Res. 32: 275-285. doi:10.1007/s11095-014-1461-9.

[35] Andreini, C., Bertini, I., Cavallaro, G., Holliday, G.L., Thornton, J.M. (2008). Metal ions in biological catalysis: From enzyme databases to general principles. J. Biol. Inorg. Chem. 13: 1205-1218. doi:10.1007/s00775008-0404-5.

[36] Cowan, J.A. (1998). Metal Activation of Enzymes in Nucleic Acid Biochemistry. Chem. Rev. 98: 1067-1088. doi:10.1021/cr960436q.

[37] Patel, V., Gajera, H., Gupta, A., Manocha, L., Madamwar, D. (2015). Synthesis of ethyl caprylate in organic media using Candida rugosa lipase immobilized on exfoliated graphene oxide: Process parameters and reusability studies. Biochem. Eng. J. 95: 62-70. doi:10.1016/j.bej.2014.12.007.

[38] Garlapati, V.K., Banerjee, R. (2013). Solventfree synthesis of flavour esters through immobilized lipase mediated transesterification. Enzyme Res. 2013. doi:10.1155/2013/367410.

[39] Kumar, P., Krishna, A.G. (2015). Physicochemical characteristics of commercial coconut oils produced in India. Grasas Aceites. 66(1): e062. doi:10.3989/gya.0228141.

[40] Shahrom, K.B.M.S.R., Tao, L.C., Yuhana, N., Norzali, N.R.A., Sien, W.C. (2010). FTIR Spectroscopy analysis of the prepolymerization of palm-based polyurethane. Solid State Sci. Technol. 18: 1-8. doi:10.1002/humu.21631.

[41] Jamwal, S., Dharela, R., Gupta, R., Ahn, J.H., Chauhan, G.S. (2015). Synthesis of crosslinked lipase aggregates and their use in the synthesis of aspirin. Chem. Eng. Res. Des. 97: 159-164. doi:10.1016/j.cherd.2014.09.010.

[42] Jamie, A., Alshami, A.S., Maliabari, Z.O., Ateih, M.A. (2017). Development and Validation of a Kinetic Model for Enzymatic Hydrolysis Using Candida rugosa Lipase. J. Bioprocess. Biotech. 07: 1-7. doi:10.4172/21559821.1000297.

[43] Nyari, N.L.D., Fernandes, I.A., BustamanteVargas, C.E., Steffens, C., de Oliveira, D., Zeni, J., Rigo, E., Dallago, R.M. (2016). In situ immobilization of Candida antarctica B lipase in polyurethane foam support. J. Mol. Catal. B Enzym. 124: 52-61. doi:10.1016/j.molcatb.2015.12.003. 